\title{
Apoptosis of Tubular Epithelial Cells in Glycogen Nephrosis During Diabetes
}

\author{
Saoussen Bamri-Ezzine, Zhu Jun Ao, Irene Londoño, Diane Gingras, and \\ Moïse Bendayan
}

Department of Pathology and Cell Biology, Université de Montréal, Montréal, Québec, Canada

\begin{abstract}
SUMMARY: The important problem of the fate of glycogen-accumulating clear cells in glycogen nephrosis is still unsettled. In this study, we examine whether apoptosis plays a relevant role in the development of diabetic glycogen nephrosis and explore the involvement of the Fas/Fas-L system and the activation of the caspase cascade. Diabetes was induced in rats by streptozotocin injection. Glycogen-accumulating clear cells were identified in renal tissues of hyperglycemic rats. They were found to be concentrated in the thick ascending limbs and distal tubules. Large cellular glycogen accumulations were confirmed by biochemical assays and enzyme-gold cytochemistry. Clear cells displayed apoptotic features such as Annexin V binding, nuclear TUNEL (terminal deoxynucleotidyl transferase-mediated deoxyuridine triphosphate nick-end labeling), and the simultaneous occurrence of Fas, Annexin V, and TUNEL positivity. Western blot analysis demonstrated enhanced expression of Fas receptor/ligand and the activation of the caspase cascade in these cells because cleaved forms of the caspase- $3,-8$, and -9 were detected. Furthermore, active caspase- 3 was located in nuclei by immunoelectron microscopy. Our results indicate that epithelial cells in thick ascending limbs and distal tubules that develop glycogen nephrosis in response to hyperglycemia undergo Fas/Fas-L mediated cell death. Thus, apoptosis could be playing a significant role in renal epithelial cell deletion during diabetes. (Lab Invest 2003, 83:1069-1080).
\end{abstract}

$A$ poptosis is a specific type of cell death crucial for maintaining the appropriate number of cells in wellorganized tissues (Hengartner, 2000). It occurs as a normal event during kidney development and following injuries. In diabetes mellitus, the abnormal metabolic environment has a major influence on renal pathologic alterations, including acute tubulo-epithelial cell hypertrophy, chronic glomerular nephropathy associated with tubular epithelial cell atrophy, and interstitial fibrosis (Nyengaard et al, 1993; Rasch, 1984; Ziyadeh and Goldfarb, 1991). The deletion of individual renal tubular cells by apoptosis could well be a mechanism underlying tubular atrophy (Schumer et al, 1992; Woo, 1995). Ortiz et al (Ortiz et al, 1997) suggested that the metabolic changes occurring in diabetes modulate the expression of apoptosis-regulatory genes so as to induce renal proximal tubular epithelial cell death.

The glycogen nephrosis, characteristic of diabetic nephropathy, has been extensively investigated (Holck and Rasch, 1993; Meyer et al, 1998; Nannipieri et al, 2001; Rasch, 1984, 1991). Rasch and Holck (Holck and Rasch, 1993; Rasch, 1984, 1991) reported that the lesion is confined to the distal tubules, including the thick ascending limbs (TALs) in the cortex and

\section{DOI: 10.1097/01.LAB.0000078687.21634.69}

Received April 8, 2003.

The present study was supported by the Canadian Institutes of Health Research and the Association Diabète Québec.

Address reprint requests to: Dr. Moise Bendayan, Department of Pathology and Cell Biology, Université de Montréal, C.P. 6128, Succ. Centre-ville, Montréal, Québec, H3C 3J7, Canada. E-mail: moise.bendayan@ umontreal.ca the outer stripe of the outer medulla (OSOM). The cytoplasm of most abnormal cells is loaded with glycogen particles, and the lesion could be prevented by insulin treatment (Rasch, 1991; Rasch and Cøtzsche, 1988). The glycogen deposition has been detected in cells of the cortical TAL of diabetic rat kidney as early as 24 hours following injection of streptozotocin and increased steadily afterward (Hennigar et al, 1987). An important and still unsettled problem concerning this lesion is the fate of the abnormal cells. These cells may die either by necrosis or apoptosis. Because recent studies have shown that multiple cytotoxic stimuli, well known to cause necrosis, can lead to apoptosis in certain conditions (Lieberthal and Levine, 1996), we attempted to investigate the eventuality of apoptosis in glycogen nephrosis during diabetes.

The factors that initiate and regulate programmed cell death in the kidney are just beginning to be studied. A series of protein systems appear to regulate apoptotic events. Fas/Apo-1/CD95, a transmembrane protein of the TNF receptor family, leads to apoptosis when activated by its ligand. In normal kidney, Fas antigen is expressed at very low levels mainly by proximal tubular cells (Lorz et al, 2000; Schelling et al, 1998). Despite previous studies demonstrating that Fas-mediated renal tubular cells apoptosis leads to chronic renal failure (Schelling et al, 1998; Schelling and Cleveland, 1999), no report concerning its involvement in diabetic glycogen nephrosis has been put forward.

The purpose of the present study is to assess whether apoptosis plays a role in the development of 
the diabetic nephropathy, and if so, to explore the cascade of the signaling pathway leading to the apoptotic cell-death process.

\section{Results}

The diabetic animals displayed significantly higher blood glucose levels and lower body weights than the age-matched controls and streptozotocin-injected normoglycemic animals. Blood glucose levels averaged $30.5 \pm 2.6 \mathrm{mmol} / \mathrm{L}$ for the diabetic rats versus $6.2 \pm 0.7 \mathrm{mmol} / \mathrm{L}$ for the age-matched control rats; body weight averaged $210 \pm 38 \mathrm{~g}$ for the diabetic animals versus $510 \pm 58 \mathrm{~g}$ for the controls $(n=10)$. We examined renal tissues of streptozotocin-injected animals (12 weeks) that did not respond to the drug and did not develop hyperglycemia (body weight 530 $\pm 44 \mathrm{~g}$, glycemia $7.1 \pm 1.9 \mathrm{mmol} / \mathrm{L})$. In such tissues no clear cells were detected, and the renal glycogen concentration was similar to that of control animals $(172 \pm 61 \mu \mathrm{g} / \mathrm{g}$ versus $153 \pm 20 \mu \mathrm{g} / \mathrm{g}$ kidney wet weight). Thus, the streptozotocin-injected normoglycemic rats were considered as one of our controls indicating that streptozotocin per se does not induce glycogen accumulation.

\section{Characteristics of Glycogen Nephrosis}

By light microscopy, glycogen nephrosis in diabetic animals was characterized by the presence of tubular epithelial cells displaying intact cell membrane, vacuolated cytoplasm, chromatin condensation, and even nuclear pyknosis. We refer to these epithelial cells as "clear cells" (Fig. 1). No inflammatory response was detected around the lesion. The nephrosis occurred predominantly at the level of the TAL and distal tubules in the cortex and outer medulla (Fig. 1, A and B) but not in the inner medulla. Normoglycemic animals did not display such glycogen nephrosis.

Evaluation of the extent of glycogen nephrosis in the cortex and in outer medulla by morphometry demonstrated that the area of clear cells represents $7.1 \pm$ $0.6 \%$ of the cortex, $10.5 \pm 0.9 \%$ of the OSOM, and $4.4 \pm 0.4 \%$ of the inner stripe of the outer medulla.

Electron microscopy revealed large amounts of glycogen granules distributed throughout the cytoplasm of clear cells that contained only few organelles, mostly located close to the cell membrane (Fig. 1C). By applying enzyme-gold cytochemistry (Bendayan, 1984), the cytoplasm was labeled by the amylase-gold complex (Fig. 1D), confirming the glycogen nature of the deposits. Pyknotic nuclei were found in clear cells (Fig. 1E).

\section{Characterization of Renal Fractions}

Fractions of thick ascending limbs and distal tubules (DTF) were isolated from normal and diabetic rat kidneys. To assess the enrichment of these fractions, we analyzed by Western blot the expression of TammHorsfall protein (THP), a marker of TAL and distal tubules (Rasch et al, 1995), and compared it to glomerular fractions and to total renal tissues (Fig. 2A).
THP expression in the DTF displayed approximately a 2.5-fold increase when compared with the entire kidney and a 16-fold increase when compared with glomerular fractions from the same animals. These results are good indication of the purity of our DTF.

Glycogen concentration in the different renal fractions is shown in Figure 2B. DTF from diabetic animals display approximately a 6 -fold increase in glycogen concentration as compared with those from control animals and a 60-fold increase when compared with the glomerular fractions from the same diabetic animals. These data clearly indicate that the DTF isolated from diabetic animals are significantly enriched in glycogen. It also reflects on the purity of the DTF.

\section{Glycogen Synthase Kinase 3- $\beta$}

The levels of phosphorylated GSK3- $\beta$ in DTF from diabetic animals were significantly lower than in those from control animals $(p<0.001)$ (Fig. 2C). The changes in GSK3- $\beta$ phosphorylation could not be explained by differences in GSK3- $\beta$ protein content because the latter, as determined by Western blot, did not differ from the DTF of control animals (Fig. 2D).

\section{Detection of Apoptosis: Annexin V and TUNEL}

Figure 3 shows light and electron microscopy images of renal sections from diabetic animals labeled for apoptotic markers. Upon injection of Annexin $\mathrm{V}$ in renal artery, a large number of clear cells displayed strong membranous signals for Annexin V (Fig. 3A), which binds to phosphatidylserine groups transposed to the outer membrane leaflet during the early stages of apoptosis. This was confirmed by electron microscopy (Fig. 3B). In normal animals, the apical membrane of few tubular cells, particularly in TAL, was labeled for Annexin V, but in contrast to tissues from diabetic animals, the intensity of this staining was low and sparse (Fig. 4A). Control experiments using antigen-preadsorbed antibodies confirmed the specificity of the immunocytochemical signals at the light and electron microscope levels (not shown).

Numerous TUNEL (terminal deoxynucleotidyl transferase-mediated deoxyuridine triphosphate nickend labeling)-positive nuclei were assigned to clear cells in diabetic rat kidney, some showing margination of their condensed chromatin (Fig. 3C), whereas very few TUNEL-positive cells were observed in TAL and distal tubules of control animals (Fig. 4B). There was no morphologic difference between tissues from the left or the right kidney, which indicates that clamping blood flow for about 3 to 5 minutes after injecting Annexin V-FITC had no effect on TUNEL staining.

\section{Fas and Fas-L Expression}

To determine whether clear cells undergo apoptosis by a Fas-dependent mechanism, kidney sections were examined for Fas. Almost all of the clear cells displayed strong membrane immunostaining for Fas (Fig. 3D), which was confirmed by electron microscopy (Fig. 3E). The double-stainings of Annexin 

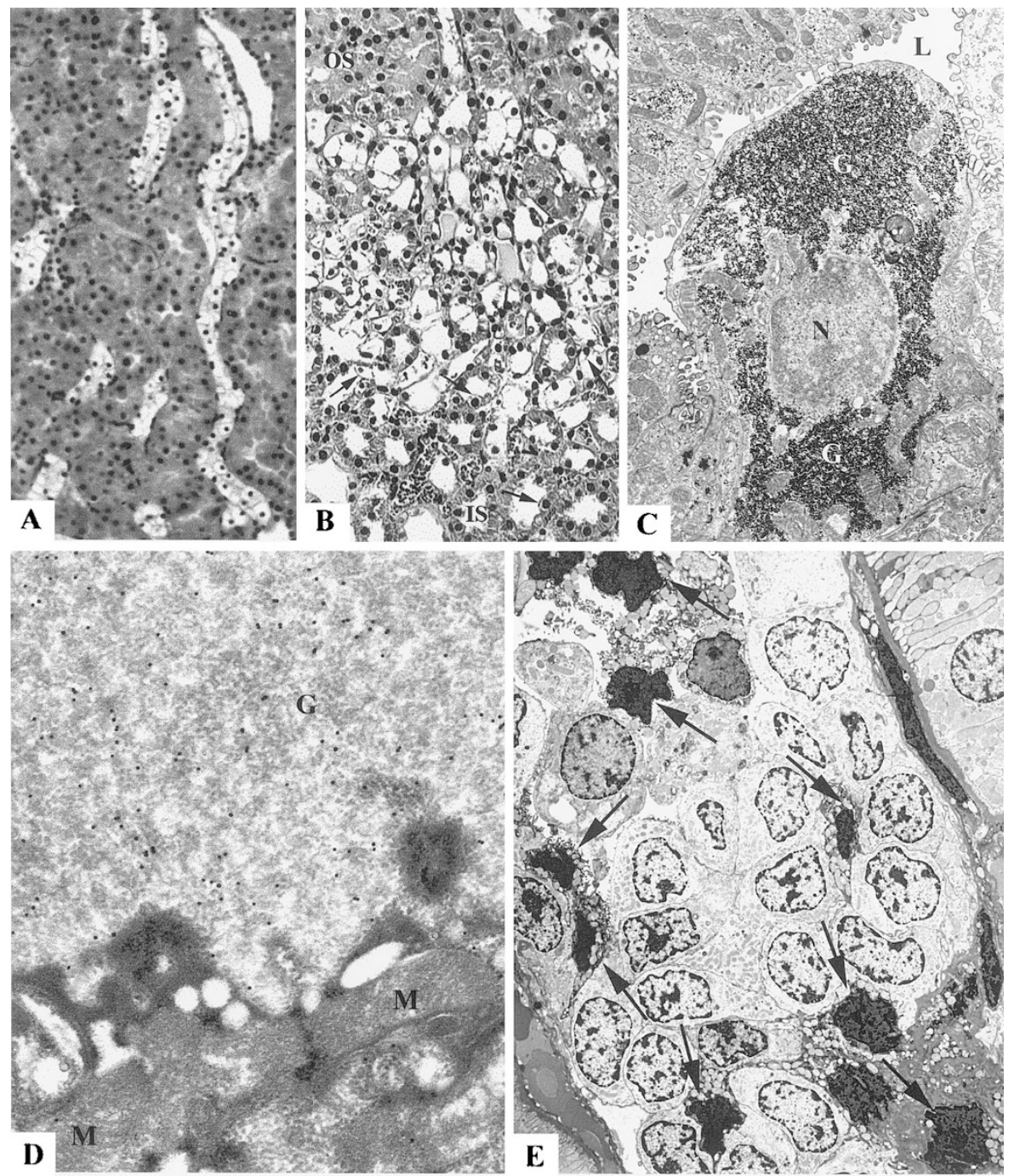

\section{Figure 1.}

Characteristics of the glycogen-accumulating clear cells. (A) Light microscopy. Renal cortex from a diabetic rat. Clear cells are characterized by a vacuolated cytoplasm at the level of the distal tubules and thick ascending limbs (TALs) due to extraction of glycogen during tissue processing (hematoxylin and eosin, $\times 250$ ). (B) Light microscopy. Renal outer (OS) and inner (IS) stripes of the outer medulla from a diabetic rat. Arrows indicate clear cells in the IS (hematoxylin and eosin, $\times 120$ ). (C) Electron microscopy. Cortical TAL from a diabetic rat kidney. The tissue was fixed by the one-step fixation-staining method. The cytoplasm of the cell is filled with glycogen particles $(G) . N=$ nucleus; $L=$ lumen of distal tubules $(\times 6000)$. (D) Electron microscopy. Renal distal tubule from a diabetic rat. Amylase-gold cytochemical labeling of a clear cell. The glycogen deposits are labeled by gold particles. Cellular organelles such as mitochondria (M) are devoid of labeling $(\times 12,000)$. (E) Electron microscopy. Renal distal tubule with clear cells from a diabetic rat. Many of these cells have pyknotic nuclei $($ arrows $)(\times 3100)$.

V/TUNEL (Fig. 5A), Fas/TUNEL (Fig. 5B), and Fas/ Annexin $V$ (Fig. 5, $C$ to $E$ ) revealed the simultaneous occurrence of Annexin V, Fas, and TUNEL reactions in clear cells.

To further evaluate whether Fas expression is regulated in diabetes, Fas protein levels were determined by Western blot in DTF. Figure 6A shows an increase in Fas protein levels in DTF isolated from diabetic animals as compared with age-matched controls.

To investigate whether these cells express Fas- $L$, DTF were probed for Fas-L by Western blot. Figure 6B demonstrates that DTF from diabetic animals display a 3-fold increase in Fas-L levels as compared with those of control animals. These data clearly indicate that Fas and Fas- $L$ expression are enhanced in clear cells.
We also assessed whether $\mathrm{Bcl}-2$ protein expression is modulated in clear cells. Figure $6 \mathrm{C}$ shows that $\mathrm{Bcl}-2$ levels are decreased significantly in DTF from diabetic animals, which suggests that the antiapoptotic proteins are down-regulated in glycogen-accumulating clear cells.

\section{Caspases Activation}

To test whether the caspase cascade is activated in clear cells, DTF were processed for Western blot analysis using specific polyclonal antibodies that recognize the proform and cleaved products of the individual caspase- 3 , caspase- 8 , and caspase- 9 . Immunoblot analysis of caspase-8 (Fig. 6D) showed the appearance of the smaller bands 25-kd and 12-kd, 
A

\section{Tamm-Horsfall protein}

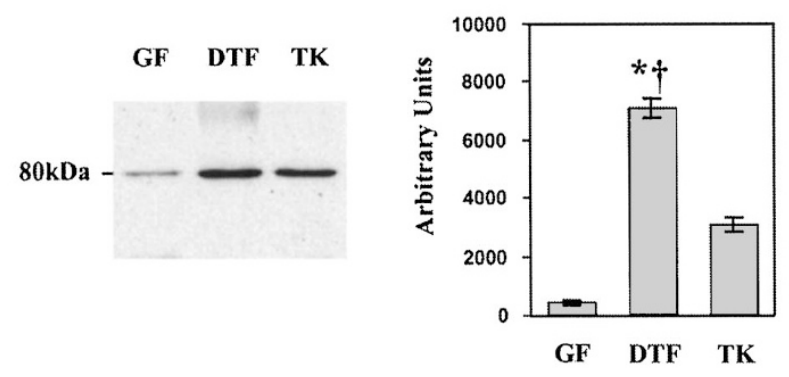

C

\section{GSK3 $\beta$ phosphorylation}
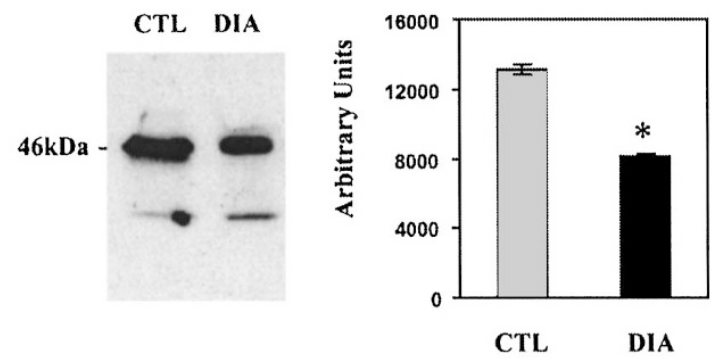

B

\section{Glycogen content}

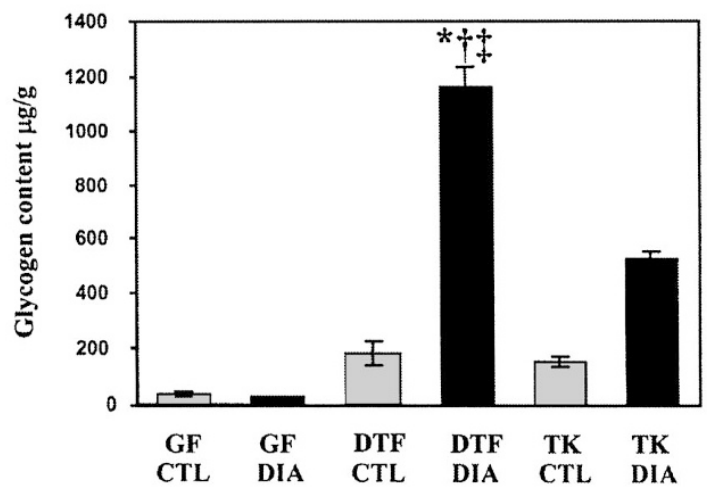

D

\section{GSK3 3 content}

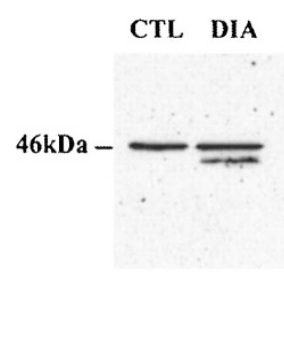

Figure 2.

(A) Solubilized glomerular fractions (GF), thick ascending limb and distal tubules fractions (DTF), and total kidney (TK) proteins from control animals were resolved by $7.5 \%$ SDS-PAGE and analyzed by immunoblotting with an anti-Tamm-Horsfall protein antibody. Representative immunoblot (left) and densitometry evaluation (right), respectively. The THP expression in the DTF displayed approximatively a 2.5 -fold increase when compared with the TK ( $f p<0.05)$ and a 16 -fold increase when compared with the GF fractions ( ${ }^{*} p<0.001$ ). Results are representative of three independent experiments in which tissues from three rats were pooled. (B) Glycogen content in GF, DTF, and TK from control (CTL, gray bars) and diabetic rats (DIA, black bars). The glycogen content is expressed as $\mu \mathrm{g} / \mathrm{g}$ renal fraction wet weight. TDL fractions from diabetic animals displays approximately a 6-fold increase in glycogen concentration as compared with the TDL fractions from control animals ( ${ }^{*} p<0.001$ ), a 60 -fold increase when compared with the GF ( $\left.\nmid p<0.001\right)$, and a 2-fold increase when compared with TK from diabetic animals ( $\left.¥ p<0.001\right)$. Results are representative of five independent experiments. (C), (D) Solubilized DTF proteins from control (CTL, gray bars) and diabetic rats (DIA, black bars) were resolved by $12.5 \%$ SDS-PAGE and analyzed by Western blot with anti-phospho-GSK3- $\beta$ (Ser-9) antibody (C) or anti-GSK3- $\beta$ antibody (D). The levels of phosphorylated GSK3- $\beta$ in DTF from diabetic animals were significantly lower than those from control animals ( ${ }^{*} p<0.001$ ), whereas total GSK3- $\beta$ protein content is similar in the DTF from control and diabetic animals $(p=0.07)$. Results are representative of three independent experiments in which tissues from three rats were pooled.

with a concurrent reduction of the amount of the procaspase enzyme p55 and the receptor-associated 43-kd in the TDL fractions from diabetic animals. Densitometry evaluation showed that $74 \%$ of $43-\mathrm{kd}$ was cleaved in the TDL fractions from diabetic animals, whereas only $2.5 \%$ of $43-k d$ was cleaved in the DTF from control animals.

The anti-caspase- 9 antibody that we used detects 50-kd and 36-kd proteins corresponding to the proform of caspase- 9 and the processed large subunit, respectively. Immunoblot analysis showed that $79 \%$ of the procaspase- 9 was cleaved in the DTF from diabetic animals, whereas only $22 \%$ was cleaved in those from control animals (Fig. 6E).

Immunoblot analysis of caspase-3 using a polyclonal antibody detecting both the proform enzyme and the processed large subunit revealed an increase in the large 20-kd subunit in the DTF isolated from diabetic animals, with a concurrent reduction in the amounts of procaspase-3 (Fig. 6F). In fact, densitometry evaluation showed that $63 \%$ of caspase- 3 was cleaved in the TDL fractions from diabetic animals, whereas only $18 \%$ was cleaved in those from control animals. The consistent $30-\mathrm{kd}$ band detected in our 


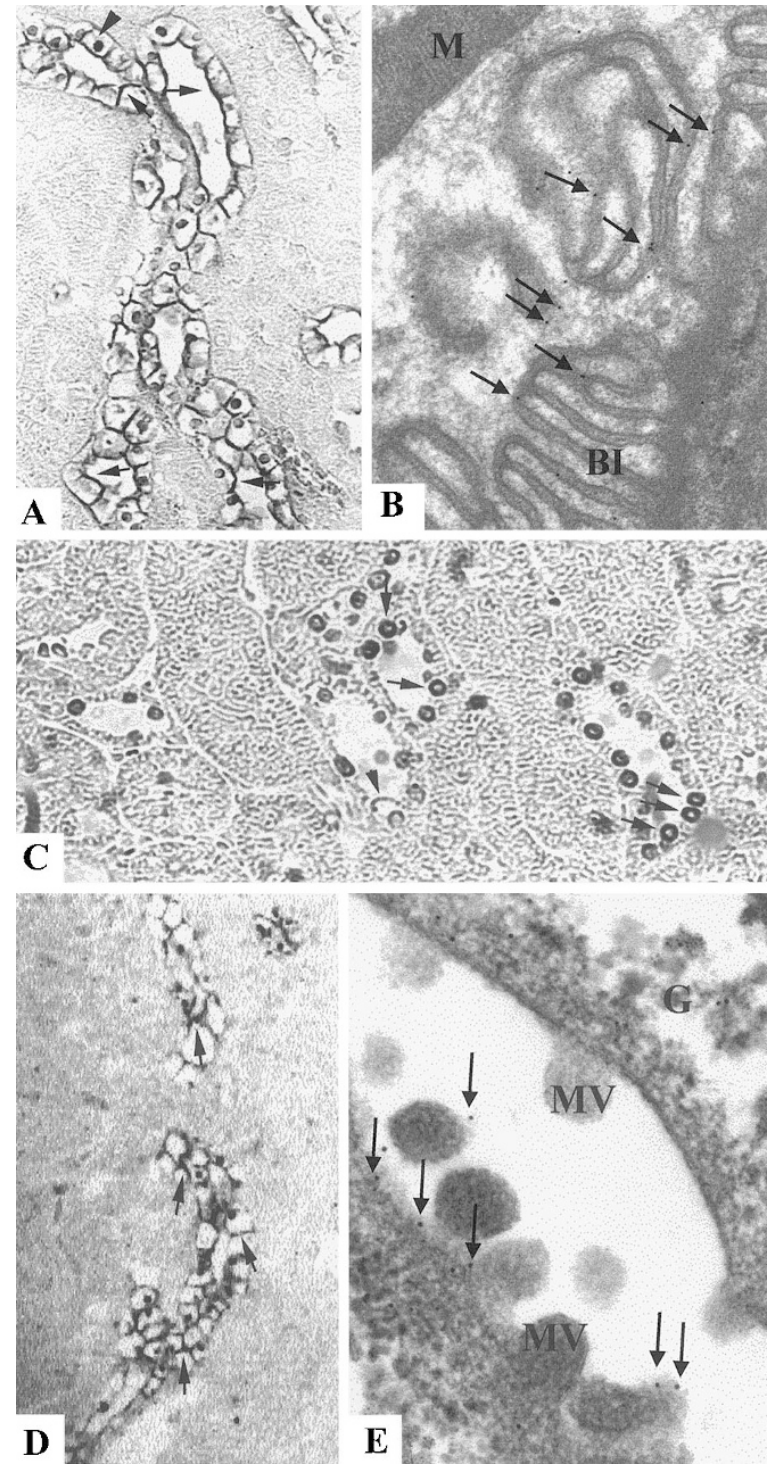

Figure 3.

(A) Light microscopy. Annexin V-FITC staining of renal tissue of a diabetic rat. No counterstaining was applied. The clear cells show Annexin V-FITC labeling at the plasma membrane (arrows). Some nuclei display a nonspecific staining (arrowhead, $\times 250$ ). (B) Electron microscopy. Clear cell in the renal tissue of a diabetic rat. Localization of Annexin V-FITC by the protein A-gold technique. The gold particles revealing Annexin V-FITC are present on the membrane of the basal infoldings (arrows, BI). Mitochondria (M) are devoid of labeling $(\times 17,000)$. (C) Light microscopy. Renal tissue of a diabetic rat. TUNELpositive nuclei are present in the distal tubules and thick ascending limbs. Some nuclei show margination of this condensed chromatin (arrows). One of the distal tubular cells is clearly a characteristic clear cell (arrowhead). No counterstaining was applied $(\times 260)$. (D) Light microscopy. Diabetic rat kidney. Clear cells are positively stained with the anti-Fas antibody (arrow, $\times 120$ ). (E) Electron microscopy. Apical membrane of clear cells in renal tissue of a diabetic rat. Localization of Fas by the protein A-gold technique. Gold particles revealing Fas antigenic sites are associated with the apical membrane (arrows). MV = microvilli; $\mathrm{G}=$ glycogen particles $(\times 31,000)$.

samples is not caspase- 3 because it was detected in MCF7 cells, which lack caspase-3 protein (Kirsch et al, 1999). Densitometry evaluation of this band showed equivalent amounts in DTF from control and diabetic animals (Fig. 6F). Immunoblot analysis of DTF using an antibody that recognizes specifically the active form of caspase- 3 revealed that the 18 -kd subunit is only

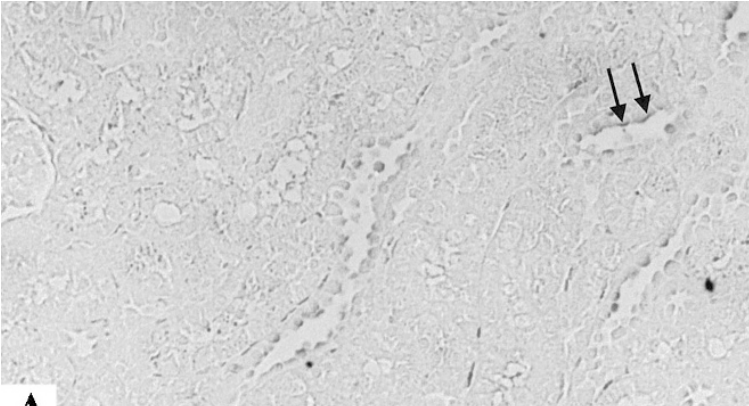

A

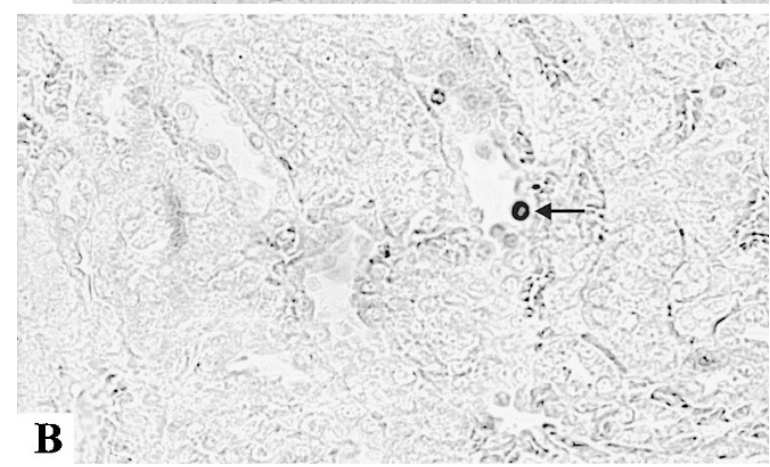

Figure 4.

(A) Light microscopy. Normal rat kidney. Labeling for Annexin $V$ is sparse and mainly located at the surface of some thick ascending limbs and distal tubular cells (arrows, $\times 120)$. (B) Light microscopy. Normal rat kidney. Very few TUNEL-positive cells are observed, some of them presenting margination of their condensed chromatin $($ arrow, $\times 200)$.

detected in DTF from diabetic animals (not shown). Immunocytochemistry using the same antibody was able to locate this cleaved caspase- 3 in clear cells. The labeling was concentrated in nuclei (Fig. 6G). Quantitative evaluation (Table 1) demonstrated that the labeling on nuclei of clear cells was 4.5-fold higher than that on nuclei of nonclear cells (distal tubule cells that do not accumulate glycogen) in renal tissues of diabetic animals and 6.5-fold higher than that on nuclei of distal tubule cells of control animals.

\section{Discussion}

Apoptosis is an important cause for cell death in acute and chronic renal diseases (Schumer et al, 1992; Woo, 1995). In the present study, we demonstrate that glycogen-accumulating clear cells do undergo apoptosis. The combination of Annexin $\mathrm{V}$ labeling and TUNEL technique proved to be efficient in detecting apoptotic cells in renal tissue (Ansari et al, 1993; Blankenberg et al, 1998). The variety of nuclear morphology in the abnormal cells, which included normal profile, chromatin condensation, and even pyknosis, indicates that the cells are at different stages of cell death.

The Fas signaling pathway system for apoptosis was the focus of the present investigation because it is involved in the pathogenesis of tissue injury, particularly in renal tubular epithelial cells (Porter et al, 2000; Schelling et al, 1998; Schelling and Cleveland, 1999). The enhanced Fas receptor/ligand expression, to- 

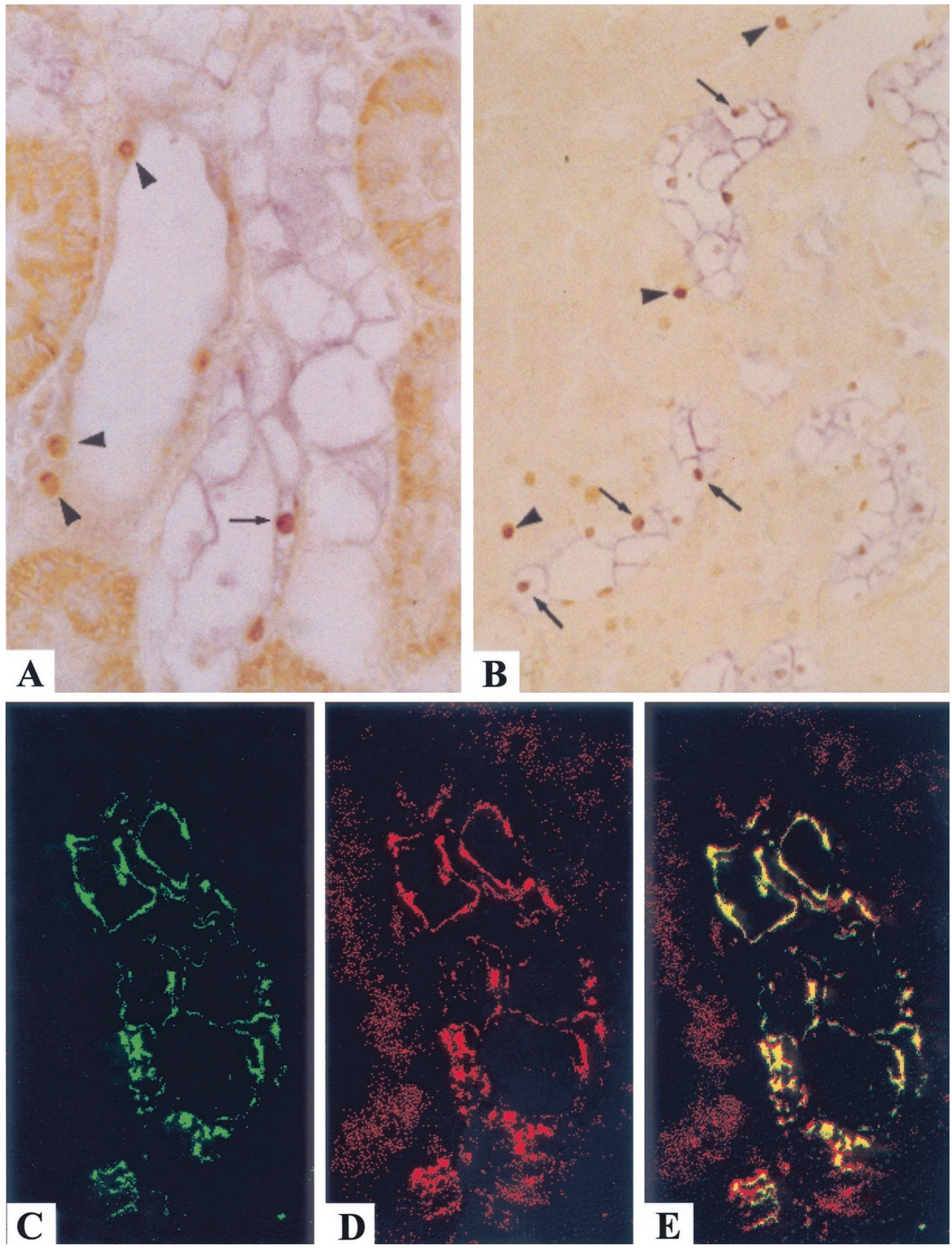

\section{Figure 5.}

(A) Double-labeling of Annexin V and TUNEL in a renal tissue section of a diabetic rat. Many clear cells show Annexin V-FITC labeling at the plasma membrane (blue staining). Some cells are double-labeled for Annexin V and TUNEL (arrow), whereas few nonclear cells are only TUNEL positive (arrowheads, $\times 250$ ). (B) Double-labeling of Fas and TUNEL in a renal tissue section of a diabetic rat. A large number of clear cells show Fas labeling at the plasma membrane (blue staining). Some cells are double-labeled for Fas and TUNEL (arrows). Few nonclear cells are only TUNEL positive (arrowheads, $\times 750)$. (C), (D), and (E) Doubleimmunofluorescence staining visualized by confocal laser scanning microscopy. Renal tissue from a diabetic rat. Separate scannings in the same focal plane for fluorescein green staining (revealing Annexin V-FITC immunoreactive cells, C) and for rhodamine red staining (revealing Fas immunoreactive cells, D). (E) Merging $\mathrm{C}$ and D. Strong simultaneous occurrence (yellow staining) of both Annexin V-FITC and Fas $(\times 600)$. 
A

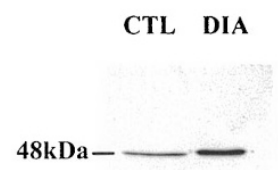

C

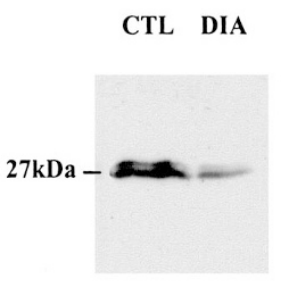

E
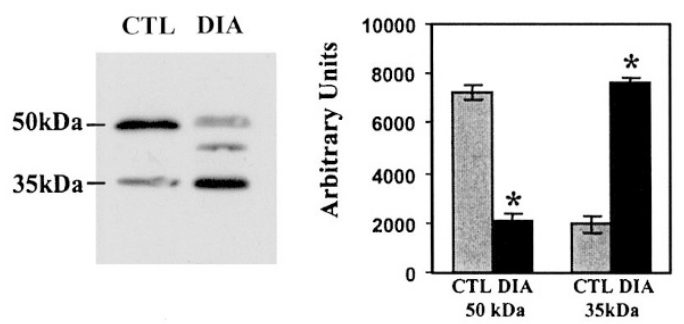

Fas

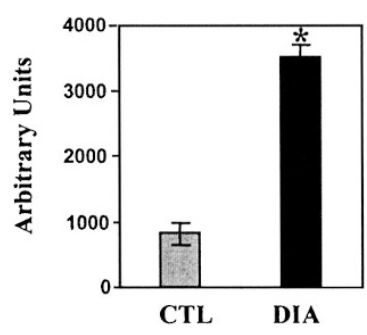

Bcl-2

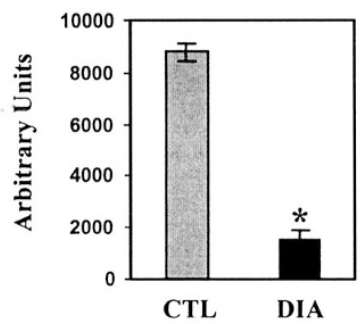

B

D

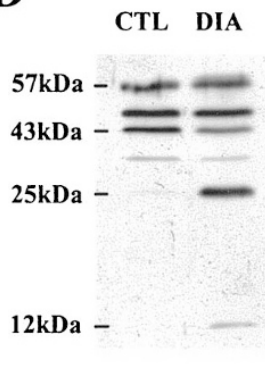

F

CTL DIA

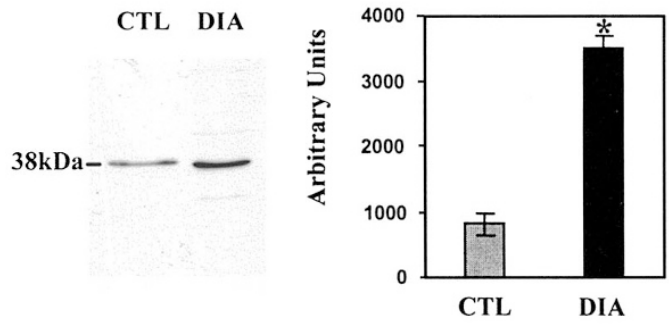

Caspase-8

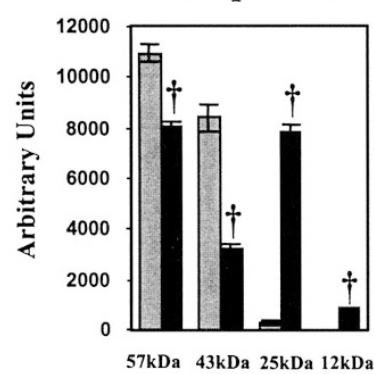

\section{Caspase-3}

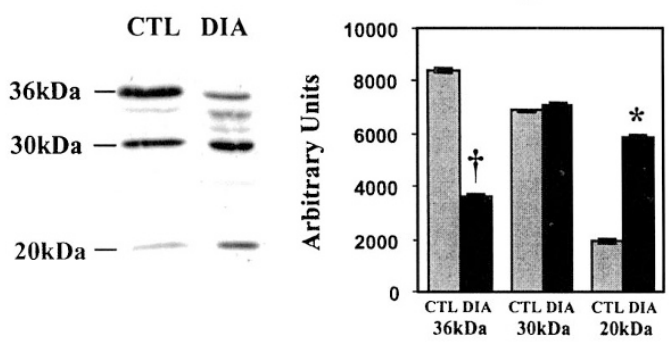

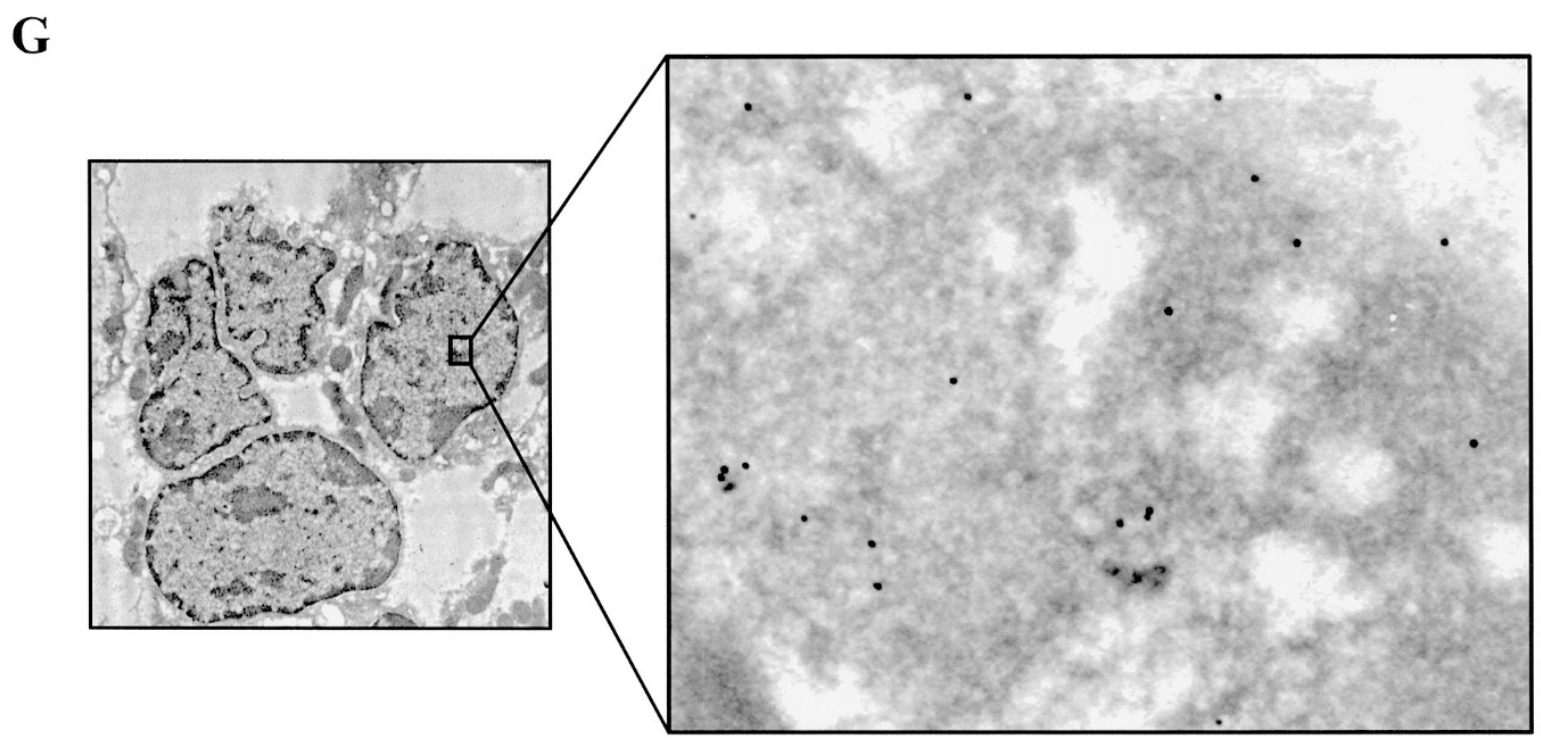

Figure 6.

Solubilized thick ascending limb and distal tubules fraction proteins from control (gray bars) and diabetic rats (black bars) were resolved by $16.5 \%$ SDS-PAGE and analyzed by immunoblotting with anti-Fas (A), anti-Fas-L (B), anti-Bcl-2 (C), anti-caspase-8 (D), anti-caspase-9 (E), and anti-caspase-3 (F) antibodies. Representative Western blots (left) and densitometry evaluations (right), respectively ( ${ }^{*} p<0.001$ vs control; $\dagger p<0.05$ vs control). Results from three independent experiments. $\mathrm{CTL}=$ control rats; $\mathrm{DIA}=$ diabetic rats. $(\mathrm{G})$ Electron micrograph. Active caspase- 3 immunolabeling of clear cells nuclei from diabetic rat kidney (left) $\times 3600$. Enlargement of small area of the nucleus of one clear cell. Gold particles are present over the nuclei of clear cells (right) $\times 63,000$. 
Table 1. Immunolabeling Density for Active Caspase-3 in Nuclei of Renal Epithelial Tubular Cells in Normal and Diabetic Rats (gold particles $/ \mu \mathrm{m}^{2}$ )

Diabetic animals ${ }^{a}$

\begin{tabular}{cccc}
\cline { 2 - 3 } $\begin{array}{c}\text { Normal animals } \\
\text { TAL cells }\end{array}$ & Clear cells & Nonclear cells & $\begin{array}{c}\text { Control of specificity }{ }^{a} \\
\text { Clear cells }\end{array}$ \\
\hline $1.1 \pm 0.2$ & $7.7 \pm 1.3^{b}$ & $1.5 \pm 0.5$ & $1.1 \pm 0.2$ \\
\hline
\end{tabular}

TAL, thick ascending limb.

${ }^{a}$ Mean values $\pm \mathrm{SD}, \mathrm{n}=3$ animals per group

${ }^{b} p<0.001$ diabetic vs control animals; $p<0.001$ diabetic vs nonclear cells of diabetic animals.

gether with the cleavage of caspase-8, support Fasdependent mechanism-mediated apoptosis. In fact, stimulation of Fas results in aggregation of its intracellular death domain, leading to the recruitment of two proteins, FADD and procaspase-8. These, together with Fas receptor, form the death-inducing signaling complex (DISC) (Boldin et al, 1996). By association with Fas DISC, procaspase-8 is cleaved, leading to the release of the active subunits in the cytosol (Medema et al, 1997). The Fas signaling pathway has been shown to involve activation of additional caspases, such as caspase-1 and caspase-3 (Enari et al, 1996). Caspase-3, which appears to play an important role in the apoptosis effector pathway (Hengartner, 2000), was found to be activated in clear cells. Active caspase-3 cleaves many vital substrates leading to the morphologic changes of apoptotic cells (Nuñez et al, 1998). DNA fragmentation into nucleosomal fragments is the most recognizable biochemical feature in apoptosis. DNA fragmentation does occur in most clear cells as detected by the TUNEL reaction. Active caspase-3 was located in nuclei of these cells. In fact, caspase-3 is primarily in the cytoplasm and once activated is transported into the nucleus during apoptosis to gain access to its nuclear substrates, such as lamin B and nuclear pore complex proteins (Buendia et al, 1999). Other studies have already shown the presence of activated caspase-3 in the nucleus (Kuida et al, 1998; Namura et al, 1998).

The cleavage and activation of caspase- 9 in clear cells is of interest because this caspase could be activated by the Fas-mediated apoptosis that has been reported to occur in so-called "type II cells." Many data support the type I/type II concept of Fas signaling (Li et al, 1998; Luo et al, 1998; Scaffadi et al, 1998). In so-called "type I cells" (Scaffadi et al, 1998), the death signal is propagated by a caspase cascade initiated by the activation of caspase- 8 at the DISC, followed by cleavage of caspase-3 and other caspases. On the other hand, in type II cells, hardly any DISC is assembled, and the caspase cascade cannot be propagated but is amplified via the mitochondria. Thus, caspase- 8 cuts Bcl-2 family member Bid and truncated Bid activates mitochondria (Li et al, 1998), which in turn releases cytochrome $c$. The latter associates with Apaf-1 and procaspase-9 in the cytoplasm forming the apoptosome (Hengartner, 2000). This complex is then responsible for the cleavage of caspase-9, which activates further downstream caspases leading to cell death (Hengartner, 2000). We propose that clear cells are type II cells because we have demonstrated that not only caspase- 9 is activated but also that the antiapoptotic protein Bcl-2 is down-regulated. Scaffadi et al (1998) have shown that in contrast to type I cells, in type II cells, cleavage of caspase- 8 and caspase- 3 was completely blocked by overexpression of $\mathrm{Bcl}-2$. Other studies (Shimizu et al, 1996; Yang et al, 1997) have demonstrated that overexpression of $\mathrm{Bcl}-2$ can block all mitochondrial activities during apoptosis. The decrease of Bcl-2 levels in renal epithelial cells that may facilitate the activation of mitochondria and the formation of apoptosome in these cells was also reported by Ortiz et al (Ortiz et al, 1997). They have shown that high ambient glucose and diabetic state modulate the expression of apoptosis-regulatory genes leading to a decrease of the $\mathrm{Bcl}-2$ :Bax ratio in renal cortex. Ortiz and his colleagues have proposed that tubular epithelial cells are type II cells (Ortiz et al, 2000b) because they demonstrated in transfected cells that preventing the decrease in $\mathrm{Bcl}-\mathrm{xL}$, the antiapoptotic member of the $\mathrm{Bcl}-2$ family, protects against apoptosis induced by nephrotoxins and lethal receptors (Lorz et al, 1998; Ortiz et al, 2000a).

We have shown that clear cells may undergo apoptosis by the Fas/Fas-L system. However, the pathway by which glycogen accumulation triggers the apoptotic machinery remains unclear. GSK3 is an unusual serine/ threonine kinase because it is inactivated by phosphorylation. GSK3 was initially identified as an enzyme that regulates glycogen synthesis. It phosphorylates and inactivates the glycogen synthase (GS), the final enzyme in glycogen biosynthesis (Embi et al, 1980). There are two closely related isoforms GSK3- $\alpha$ and GSK3- $\beta$, which are expressed ubiquitously in mammalian tissues (Woodgett, 1990). Inhibition of GSK3 by insulin results from its phosphorylation at N-terminal serine residues (serine 21 in GSK3- $\alpha$ and serine 9 in GSK3- $\beta$ ) (Cross et al, 1995). Thus, in response to insulin, the inhibition of GSK3 promotes the dephosphorylation and activation of GS, contributing to the stimulation of glycogen synthesis. Recently, GSK3 has interestingly been implicated in regulation of apoptosis. Pap and Cooper (1998) found that overexpression of GSK3 induces apoptosis in PC12 and Rat-1 cells, whereas overexpression of a catalytically inactive mutant of GSK3 prevents apoptosis induced by a phosphatidylinositol 3-kinase inhibitor. Recent work in neurons (Cross et al, 2001; Hetman et al, 2000) has lent support to the hypothesis that GSK3- $\beta$ may play a role in the regulation of apoptosis. In clear 
cells, phosphorylation levels of GSK3- $\beta$ are decreased, which leads to increase in GSK3- $\beta$ active form. The increase of active GSK3- $\beta$ would normally result in a decrease in GS activity, which would lead to a decrease in glycogen synthesis. However, we have found that glycogen accumulation in these cells is extensive. One possibility consists in the allosteric modulation of GS. The glycogen synthase is regulated by phosphorylation and dephosphorylation. When the active form $\mathrm{GS}(\mathrm{l})$ is phosphorylated by protein kinases such as GSK3, GS(I) is converted into the less active form GS(D) (Chock et al, 1980). This form is modulated allosterically and becomes active when stimulated by its allosteric modulator glucose 6-phosphate (Chock et al, 1980). Along this line, Khandelwal et al (1979) have demonstrated that in diabetic rats, the increase in kidney glycogen is associated with increases of the D form of GS and of its allosteric activator, the glucose 6-phosphate. It is tempting to speculate, therefore, that the decrease of GSK3- $\beta$ phosphorylation in clear cells may contribute not only to glycogen accumulation but also to increased rates of apoptosis leading to the development of diabetic tubulopathy.

In our study, tubular apoptosis was found to be associated with glycogen accumulation but there may be other factors of the diabetic milieu that could be involved in the induction of tubular cell death. Other studies have shown the implication of the reninangiotensin system (Kelly et al, 2002) and oxidative stress in the induction of apoptosis in tubular epithelial cells, both in culture under high-glucose conditions and in diabetes (Verzola et al, 2002; Zhang et al, 1997).

In conclusion, we provide evidence that high levels of apoptosis are present in glycogen nephrosis during diabetes and that Fas/Fas-L system may participate in the deletion of renal epithelial cells. The increased apoptosis in glycogen accumulating cells may contribute to renal tubular atrophy, the hallmark feature of end-stage diabetic nephropathy.

\section{Materials and Methods}

\section{Materials}

Routine reagents and secondary antibodies were from Sigma (Oakville, Canada). Antihuman THP antibody, mouse anti-Fas antibody, and anti-FITC antibody were from Cedarlane (Hornby, Canada). Anti-Bcl-2 antibody, rabbit anti-Fas, and anti-Fas- $L$ antibodies were from Santa Cruz Biotechnology Inc. (Santa Cruz, California). Annexin V-FITC and antiactive caspase-3 antibody were from R\&D Systems (Minneapolis, Minnesota). Anti-caspase-3, -8, and -9 antibodies were from StressGen (Victoria, Canada). Anti-GSK3- $\beta$ antibodies were from New England Biolabs (Beverly, Massachusetts).

\section{Animals}

An experimental diabetic state was induced in 100-g Sprague-Dawley male rats by a single intraperitoneal injection of streptozotocin (70 mg/ $\mathrm{kg}$ body weight). The rats became hyperglycemic within the first 72 hours and remained as such for 12 weeks. No insulin treatment was required. Regular measurements of glycosuria and body weight were carried out. At the time of death, body weight and tail vein plasma glucose were measured. Blood glucose levels were determined by using test stripes of the AccuSoft Monitoring System (Roche Diagnostics, Laval, Canada).

\section{Tissue Preparation}

At the end of the experimental time, animals were anesthetized with urethane $(0.2 \mathrm{ml} / 100 \mathrm{~g}$ body weight). The kidneys were treated as follows. For the right kidney, approximately $30 \mu \mathrm{l}$ of Annexin V-FITC $(25 \mathrm{~g} / \mathrm{l})$ was injected into the renal artery in 10 to 20 seconds. Then the main renal vessels were clamped for about 3 to 5 minutes. The kidney was removed and cut into three transversal blocks. Two of these blocks were prepared for light microscopy as described below for the left kidney. The third segment was cut and fixed in $1 \%$ glutaraldehyde in $0.1 \mathrm{~mol} / \mathrm{L}$ phosphate buffer ( $\mathrm{pH} 7.4$ ) for 24 hours at $4^{\circ} \mathrm{C}$. It was embedded in Lowicryl $\mathrm{K} 4 \mathrm{M}$ at $-20^{\circ} \mathrm{C}$ and processed for immunocytochemistry (Bendayan, 1995). Other fragments from this segment were fixed by the one-step fixationstaining method (Simionescu et al, 1972) and embedded in Epon. The left kidney was excised and decapsulated. The tissue was fixed by immersion for 24 hours in $4 \%$ paraformaldehyde in $0.1 \mathrm{M}$ HEPES buffer $7.4 \mathrm{pH}$ containing $1.5 \mathrm{~mol} / \mathrm{L} \mathrm{NaCl}, 0.05 \mathrm{~mol} / \mathrm{L} \mathrm{KCl}$, $0.01 \mathrm{~mol} / \mathrm{L} \mathrm{MgCl} 2$, and $0.018 \mathrm{~mol} / \mathrm{L} \mathrm{CaCl} 2$ at $4^{\circ} \mathrm{C}$ and embedded in paraffin. Serial sections were cut, and the first slide was stained with hematoxylin and eosin.

\section{Light Microscopy Immunohistochemistry}

For detecting Annexin V-FITC, the second tissue slide of each serial section from the right kidney was deparaffinized, rehydrated, and incubated with a rabbit anti-FITC antibody (1/50) at room temperature for 90 minutes. After rinsing 3 to 5 minutes in PBS, sections were incubated at room temperature with an antirabbit Ig $G$ conjugated to alkaline phosphatase $(1 / 200)$ for 60 minutes, washed with PBS, and developed in freshly prepared 5-bromo-4-chloro-3-indolyl phosphate and nitro-blue tetrazolium chloride substrate for 10 to 15 minutes with microscope monitoring.

For DNA fragmentation staining, the third tissue slide of each serial section was used to detect apoptotic nuclei by the TUNEL technique (Gavrieli et al, 1992) according to manufacturer's instructions (Roche Diagnostics). After deparaffinization and rehydration, the tissue sections were briefly quenched with $\mathrm{H}_{2} \mathrm{O}_{2}$ in methanol, digested with proteinase K (25 g/l) for 15 minutes, and washed. DNA fragments were elongated and labeled with fluorescein-dUTP, introduced by terminal deoxynucleotidyl transferase. Finally, bound fluorescein was stained by antifluorescein antibody conjugated with peroxidase, developed with nickelenhanced diaminobenzidine substrate with microscope monitoring. 
For Fas detection, the fourth tissue slide of each serial section was quenched with $0.3 \% \mathrm{H}_{2} \mathrm{O}_{2}$ for 30 minutes at room temperature, washed in PBS, blocked with $1 \%$ ovalbumin, and incubated overnight at $4^{\circ} \mathrm{C}$ with a rabbit anti-Fas antibody (1/300). This was followed by a rinse with PBS and incubation at room temperature with a biotinylated goat antirabbit Ig $\mathrm{G}$ secondary antibody (1/200) for 60 minutes. The bound anti-Fas-lgG-biotin was visualized using the avidin-biotin complex method with horseradish peroxidase-conjugated avidin. Diaminobenzidine was used as a substrate. Alternatively, an antirabbit lg G conjugated to alkaline phosphatase was used for 60 minutes and developed in freshly prepared 5-bromo-4-chloro-3-indolyl phosphate and nitro-blue tetrazolium chloride substrate for 10 to 15 minutes with microscope monitoring. All of the sections were mounted with Eukitt without counterstaining and were examined using a Leitz Orthoplan microscope (Leica, Montreal, Canada).

\section{Double-Labeling}

Tissue sections labeled for Annexin $V$ or Fas were subjected to TUNEL staining. The double-staining of Annexin $\mathrm{V}$ and Fas was performed using a rabbit anti-FITC antibody and a mouse anti-Fas antibody, followed by the FITC-conjugated goat antirabbit Ig G and the TRITC-conjugated goat antimouse Ig G. The sections were scanned in the same focal plane for rhodamine and fluorescein stainings with a Bio-Rad MRC 600 confocal microscope (Cambridge, Massachusetts). Images of double-immunofluorescence were collected and digitized. Fluorescein and rhodamine stainings were visualized in green and red, respectively, and the colocalization of both probes under the limits of the transverse resolution of light microscopy ( $\sim 0.25 \mathrm{~mm}$ ) resulted in an orange-yellow staining according to the intensities of the individual labelings.

\section{Electron Microscopy Enzyme-Gold and Protein-A Gold Cytochemistry}

The enzyme-gold cytochemical and the protein A-gold immunocytochemical techniques (Bendayan, 1984, 1995) were applied for the ultrastructural localization of glycogen, Annexin V, Fas, and active caspase-3. For the localization of glycogen deposits, the amylasegold complex was prepared using human salivary amylase (EC 3.2.1.1) and a colloidal-gold (15 nm) suspension at $7.5 \mathrm{pH}$ as described previously (Bendayan, 1984). Thin sections of Epon-embedded tissues were incubated for 15 minutes at room temperature with the amylase-gold complex. Grids were stained with uranyl acetate and lead citrate. Control experiments using a nonenzyme-gold complex, the albumin-gold, were carried out.

For Annexin V, Fas, and active caspase-3 detection, Lowicryl thin sections of rat renal tissues were first incubated on drop of $1 \%$ ovalbumin in PBS for 10 minutes. Subsequently, the grids were incubated on a drop of the primary antibodies rabbit anti-FITC (1/
50), rabbit anti-Fas (1/200), and rabbit antihuman active caspase- $3(1 / 40)$ overnight at $4^{\circ} \mathrm{C}$. After rinsing with $\mathrm{PBS}$, the grids were further incubated for 30 minutes with the protein A-gold complex. Finally, grids were stained with uranyl acetate prior observation with a Philips 410 electron microscope. To assess the specificity of the immunolabelings, control experiments were carried out by omitting the primary antibody and when possible by adsorption experiments with corresponding antigens.

\section{Morphometric Analysis}

Areas of clear cells were evaluated on the hematoxylin-eosin-stained sections, and results are expressed as percentage of cortex, OSOM, and inner stripe of the outer medulla areas by applying a computercontrolled video microscope image-processing system (Carl Zeiss, Toronto, Canada). For each animal $(n=5)$ and each renal zone, 135 fields from at least three tissue slides were recorded randomly.

The active caspase-3 labeling on nuclei was evaluated on 30 to 35 micrographs per animal $(n=3)$. Nuclei surface and number of gold particles were recorded and the labeling density reported in number of gold particles $/ \mu \mathrm{m}^{2} \pm$ standard deviation.

\section{Renal Fractions}

For each fractionation experiment, tissues from three rats were used and pooled. The kidneys were removed surgically and placed in ice-cold PBS (7.4 pH). For the isolation of thick ascending limb and distal tubule fractions (DTF), the area comprising the OSOM and the inner cortex was excised and minced. The tissue was resuspended in a lysis buffer $(20 \mathrm{~mm}$ Tris pH 7.5; 150 mм NaCl; 1 mм EGTA; 1\% Triton X-100; $2.5 \mathrm{~mm}$ sodium pyrophosphate; $1 \mathrm{~mm} \beta$ glycerol phosphate; $1 \mathrm{~mm}$ sodium orthovanadate; $0.2 \mathrm{mg} / \mathrm{ml}$ phenyl-methyl sulfonyl fluoride, and protease inhibitor cocktail containing serine and cysteine proteases inhibitors [50 mM EDTA, $50 \mu \mathrm{m}$ leupeptine, $15 \mu \mathrm{M}$ aprotinin, $100 \mathrm{~mm}$ AEBSF, $6.5 \mathrm{~mm}$ bestatin, $70 \mu \mathrm{M} \mathrm{E}$ 64]) and homogenized. Upon centrifugation at 8000 $\times g$, protein concentration was determined using the bicinchoninic acid method (Brown et al, 1989). The isolation of glomerular fractions was carried out as described previously (Regoli and Bendayan, 1999).

\section{Glycogen Determination}

Glycogen contents in the total kidney homogenates and in the different fractions were determined enzymatically using Sigma Diagnostics glucose kit (115), after alkaline destruction of free glucose and enzymatic hydrolysis of glycogen with $\alpha$-amyloglucosidase (EC 3.2.1.3) (Lust at al, 1975). The glycogen content is expressed as $\mu \mathrm{g} / \mathrm{g}$ renal fraction wet weight. To assess the efficiency of the destruction of free endogenous glucose in the tissues, glucose was measured before and after the alkaline treatment. Destruction of free glucose was found to be efficient to $95.6 \% \pm$ $2.9 \%$. 


\section{Western Blot}

Twenty $\mu \mathrm{g}$ of renal tissue proteins were heated for 5 minutes at $100^{\circ} \mathrm{C}$ in a sample buffer $(62.5 \mathrm{~mm}$ Tris- $\mathrm{HCl}$ $\mathrm{pH}$ 6.8, 10\% glycerol, 2\% SDS, 0.05\% bromophenol, and $5 \% \beta$-mercaptoethanol). Then they were resolved by electrophoresis on $7.5 \%, 12.5 \%$, or $16.5 \%$ SDSpolyacrylamide gels. The resolved proteins were transferred to a nitrocellulose membrane. The blots were blocked for 2 hours at room temperature with gentle agitation in the blocking buffer ( $5 \%$ nonfat milk powder in TBS and $0.1 \%$ Tween 20 ), washed, and incubated with gentle agitation overnight at $4^{\circ} \mathrm{C}$ with the primary antibodies. The dilution of the antibodies in the blocking buffer was as follow: anti-THP (1/200), anti-Fas (1/1000), anti-Fas-L (1/1000), anti-Bcl-2 (1/1000), anti-caspase-3 (1/5000), anti-caspase-3 active (1/600), anti-caspase-8 (1/1000), anti-caspase-9 (1/600), and anti-GSK3- $\beta$ antibodies (1/1000). Detection was achieved with the appropriate secondary antibodies coupled to horseradish peroxidase, followed by enhanced chemiluminescence Lumi-Light $^{\text {Plus }}$ Western blotting kit. The gels were scanned and band densities evaluated by Image Quant V1.26 program (NIH).

\section{Statistical Analysis}

Student's $t$ test was used for statistical analysis. Results are expressed as mean values \pm standard deviation. A $p$ value $<0.05$ was considered statistically significant.

\section{Acknowledgements}

This article represents part of the work required for the fulfillment of the M.Sc. program of S. BamriEzzine. We would like to acknowledge constructive comments and suggestions made by Dr. L. Cohen, University of Montreal. Z.J. Ao was an invited fellow from the Department of Histology and Embryology of the Zunyi Medical College, Zunyi, China.

\section{References}

Ansari B, Coates PJ, Greenstein BD, and Hall PA (1993). In situ end-labelling detects DNA strand breaks in apoptosis and other physiological and pathological states. J Pathol 170:1-8.

Bendayan M (1984). Enzyme-gold electron microscopic cytochemistry: A new affinity approach for the ultrastructural location of macromolecules. J Elect Microsc Techn 1:349-372.

Bendayan M (1995). Colloidal gold post-embedding immunocytochemistry. Prog Histochem Cytochem 29:1-163.

Blankenberg FG, Katsikis PD, Tait JF, Davis RE, Naumovski L, Ohtsuki K, Kopiwoda S, Abrams MJ, Darkes M, Robbins RC, Maecker HT, and Strauss HW (1998). In vivo detection and imaging of phosphatidylserine expression during programmed cell death. Proc Natl Acad Sci USA 95:6349-6354.

Boldin MP, Goncharov TM, Goltsev YV, and Wallash D (1996). Involvement of $\mathrm{MACH}$, a novel MORT1/FADDinteracting protease, in Fas/APO-1- and TNF receptorinduced cell death. Cell 85:803-815.
Brown RE, Jarvis KL, and Hyland KJ (1989). Protein measurement using bicinchoninic acid: Elimination of interfering substances. Anal Biochem 180:136-139.

Buendia B, Santa-Maria A, and Courvalin JC (1999). Caspase-dependent proteolysis of integral and peripheral proteins of nuclear membranes and nuclear pore complex proteins during apoptosis. J Cell Sci 112:1743-1753.

Chock PB, Rhee SG, and Stadtman ER (1980). Interconvertible enzyme cascade in cellular metabolism. Annu Rev Biochem 49:813-843.

Cross DA, Alessi DR, Cohen P, Andjelkovich M, and Hemmings BA (1995). Inhibition of glycogen synthase kinase-3 by insulin mediated protein kinase B. Nature 378:785-789.

Cross DA, Culbert AA, Chalmers KA, Facci L, Skaper SD, and Reith AD (2001). Selective small molecules inhibitors of glycogen synthase kinase-3 activity protect primary neurons from death. J Neurochem 77:94-102.

Embi N, Rylatt DB, and Cohen P (1980). Glycogen synthase kinase-3 from rabbit skeletal muscle: Separation from cyclicAMP-dependent protein kinase and phosphorylase kinase Eur J Biochem 107:519-527.

Enari M, Talanian RV, Wong WW, and Nagata S (1996). Sequential activation of ICE-like and CPP32-like proteases during Fas-mediated apoptosis. Nature 380:723-726.

Gavrieli Y, Sherman Y, and Ben-Sasson SA (1992). Identification of programmed cell death in situ via specific labeling of nuclear DNA fragmentation. J Cell Biol 119:493-501.

Hengartner MO (2000). The biochemistry of apoptosis. Nature 407:770-776.

Hennigar RA, Mayfield RK, Harvey JN, Ge ZH, and Sens DA (1987). Lectin detection of renal glycogen in rats with shortterm streptozotocin-diabetes. Diabetologia 30:804-811.

Hetman M, Cavanaugh JE, Kimelman D, and Xia Z (2000). Role of glycogen synthase kinase- $3 \beta$ in neural apoptosis induced by trophic withdrawal. J Neurosci 20:2567-2574.

Holck P and Rasch R (1993). Structure and segmental localization of glycogen in diabetic kidney. Diabetes 42:891-900.

Kelly DJ, Cox AJ, Tolcos M, Cooper ME, Wilkinson-Berka JL, and Gilbert RE (2002). Attenuation of tubular apoptosis by blockade of the renin-angiotensin system in diabetic Ren-2 rats. Kidney Int 61:31-39.

Khandelwal RL, Zinman SM, and Knull HK (1979). The effect of streptozotocin-induced diabetes on glycogen metabolism in rat kidney and its relationship to the liver system. Arch Biochem Bioph 197:310-316.

Kirsch DG, Doseff A, Chau BN, Lim DS, de Souza-Pinto NC, Hansford R, Kastan MB, Lazenbick YA, and Hardwick JM (1999). Caspase-3-dependent cleavage of $\mathrm{Bcl}-2$ promotes release of cytochrome c. J Biol Chem 274:21155-21161.

Kuida K, Haydar TF, Kuan CV, Taya C, Karasuyama H, Su MSS, Rakie P, and Flavell RA (1998). Reduced apoptosis and cytochrome $\mathrm{c}$ mediated caspase activation in mice lacking caspase-9. Cell 94:325-337.

Li H, Zhu H, Xu C, and Yuan J (1998). Cleavage of Bid by caspase- 8 mediates the mitochondrial damage in the Fas pathway of apoptosis. Cell 94:491-501.

Lieberthal W and Levine JS (1996). Mechanisms of apoptosis and its potential role in renal tubular epithelial cell injury. Am J Physiol 271:F477-488. 
Lorz C, Ortiz A, Catalan MP, Danoff TM, Yamasaki Y, Neilson $\mathrm{EG}$, and Egido $\mathrm{J}$ (1998). Changes in Bcl-xL expression are involved in nephrotoxic cell death (Abstract). J Am Soc Nephrol 9:596-597.

Lorz C, Ortiz A, Justo P, Gonzalez-Cuadrado S, Duque N, Gomez-Guerrero C, and Egido J (2000). Proapoptotic Fas ligand is expressed by normal kidney tubular epithelium and injured glomeruli. J Am Soc Nephrol 11:1266-1277.

Luo X, Budihardjo I, Zou H, Slaughter C, and Wang X (1998). $\mathrm{Bid}, \mathrm{a} \mathrm{Bcl}-2$ interacting protein, mediates cytochrome $\mathrm{C}$ release from mitochondria in response to activation of cell surface death receptors. Cell 94:481-490.

Lust WD, Passonneau JV, and Crites SK (1975). The measurement of glycogen in tissues by amylo- $\alpha-1,4-\alpha 1,6$ glucosidase after the destruction of preexisting glucose. Anal Biochem 68:328-331.

Medema JP, Scaffidi C, Kischkel FC, Shevshenco A, Mann M, Krammer PH, and Peter ME (1997). FLICE is activated by association with the CD95 death-inducing signaling complex (DISC). EMBO J 16:2794-2804.

Meyer C, Stumvoll M, Nadkarni V, Dostou J, Mitrakou A, and Gerich J (1998). Abnormal renal and hepatic glucose metabolism in type 2 diabetes mellitus. J Clin Invest 102:619-624.

Namura S, Zhu J, Fink K, Endres M, Srinivasan A, Tomaselli KJ, Yuan J, and Moskowitz MA (1998). Activation and cleavage of caspase-3 in apoptosis induced by experimental cerebral ischemia. J Neurosci 18:3659-3668.

Nannipieri M, Lanfranchi A, Santerini D, Catalano C, Van de Werve G, and Ferrannini E (2001). Influence of long-term diabetes on renal glycogen metabolism in the rat. Nephron 87:50-57.

Nuñez G, Benedict MA, Hu Y, and Inohara N (1998). Caspases: The proteases of the apoptotic pathway. Oncogene 17:3237-3245.

Nyengaard JR, Flyvbjerg A, and Rasch R (1993). The impact of renal growth, regression and regrowth in experimental diabetes mellitus on number and size of proximal and distal tubular cells in the rat kidney. Diabetologia 36:1126-1131.

Ortiz A, Lorz C, Catalan MP, Danoff TM, Yamasaki Y, Egido $\mathrm{J}$, and Neilson EG (2000a). Expression of apoptosis regulatory proteins in tubular epithelium stressed in culture or following acute renal failure. Kidney Int 57:969-981.

Ortiz A, Lorz C, Catalan MP, Justo P, and Egido J (2000b). Role and regulation of apoptotic cell death in the kidney. Y2K update Front Biosci 5:735-749.

Ortiz A, Ziyadeh FZ, and Neilsonff EG (1997). Expression of apoptosis-regulatory genes in renal proximal tubular epithelial cells exposed to high ambient glucose and in diabetic kidneys. J Invest Med 45:50-56.

Pap M and Cooper GM (1998). Role of glycogen synthase kinase-3 in the phosphatidyl 3-kinase/Akt cell survival. J Biol Chem 273:19929-19932.

Porter CJ, Ronan JE, and Cassidy MJD (2000). Fas/Fasligand antigen expression and its relationship to increased apoptosis in acute renal transplant rejection. Transplantation 69:1091-1094.

Rasch R (1984). Tubular lesions in streptozotocin diabetic rats. Diabetologia 27:32-37.
Rasch R (1991). Growth and regression of kidneys in experimental diabetes before and after insulin treatment. A morphometric study of glomeruli, tubules and interstitium (Abstract). J Am Soc Nephrol 2:296.

Rasch R and Cøtzsche O (1988). Regression of glycogen nephrosis in experimental diabetes after pancreatic islet transplantation. Acta Pathol Microbiol Immunol Scand 96: 749-754.

Rasch R, Torffvit O, Bochmann S, Jensen PK, and Jacobson NO (1995). Tamm-Horsfall glycoprotein in streptozotocin diabetic rats: A study of kidney in situ hybridation, immunocytochemistry and urinary excretion. Diabetologia 38:525535.

Regoli M and Bendayan M (1999). Expression of integrins in glomerular tissue of streptozotocin-induced diabetic rats. Biochem Cell 77:71-78.

Scaffadi C, Fulda S, Srinivasan A, FriesenC, Li F, Tomaselli KJ, Debatin KM, Krammer PH, and Peter ME (1998). Two CD95 (APO1/Fas) signaling pathways. EMBO J 17:16751687.

Schelling JR and Cleveland RP (1999). Investment of Fasdependent apoptosis in renal tubular epithelial cell deletion in chronic renal failure. Kidney Int 56:1313-1316.

Schelling JR, Nkemere N, Kopp JB, and Cleveland RP (1998). Fas-dependent fratricidal apoptosis is a mechanism of tubular epithelia cell deletion in chronic renal failure. Lab Invest 78:813-824.

Schumer M, Colombel MC, Sawczuk IS, Gobe G, Connor J, O'Toole KM, Olsson CA, Wise G, and Buttyan R (1992). Morphologic, biochemical, and molecular evidence of apoptosis during reperfusion phase after brief periods of renal ischemia. Am J Pathol 140:831-838.

Shimizu S, Eguchi $Y$, Kamiike W, Matsuda $H$, and Tsujimoto $Y$ (1996). Bcl-2 expression prevents activation of the ICE protease cascade. Oncogene 12:2251-2257.

Simionescu N, Simionescu M, and Palade GE (1972). Permeability of intestinal capillaries: Pathway followed by dextrans and glycogens. J Cell Biol 53:365-392.

Verzola D, Bertolotto MB, Villaggio B, Ottonello L, Dallegri F, Frumento G, Berruti V, Gandolfo MT, Garibotto G, and Deferran G (2002). Taurine prevents apoptosis induced by high ambient glucose in human tubule renal cells. J Investig Med 50:443-451.

Woo D (1995). Apoptosis and loss of renal tissues in polycystic kidney diseases. N Engl J Med 333:18-25.

Woodgett JR (1990). Molecular cloning, and expression of glycogen synthase kinase-3/factor A. EMBO J 9:2431-2438.

Yang J, Liu X, Bhalla K, Kim CN, Ibrado AM, Cai J, Peng TI, Jones DP, and Wang X (1997). Prevention of apoptosis by $\mathrm{Bcl}-2$ : Release of cytochrome $\mathrm{c}$ from mitochondria blocked. Science 275:1129-1132.

Zhang W, Khanna P, Chan LL, Campbell G, and Ansari NH (1997). Diabetes-induced apoptosis in rat kidney. Biochem Mol Med 61:58-62.

Ziyadeh FN and Goldfarb S (1991). The renal tubulointerstitium in diabetes mellitus. Kidney Int 39:464-475. 